Tropical Journal of Pharmaceutical Research September 2015; 14 (9): 1629-1634

ISSN: 1596-5996 (print); 1596-9827 (electronic)

(C) Pharmacotherapy Group, Faculty of Pharmacy, University of Benin, Benin City, 300001 Nigeria.

All rights reserved.

Available online at http://www.tjpr.org

Original Research Article

http://dx.doi.org/10.4314/tjpr.v14i9.12

\title{
Effect of Erythropoietin on Microvascular Anastomosis in Rat
}

\author{
Sadık Şentürk ${ }^{1 \star}$, Zeynep Karaçor ${ }^{2}$, Zekeriya Tosun², Adem Özkan, M Cihat \\ Avunduk ${ }^{4}$ and Murat Zümrüt ${ }^{5}$ \\ ${ }^{1}$ Mevlana (Rumi) University Hospital, ${ }^{2}$ Selcuk University Hospital, ${ }^{3}$ Department of Plastic and Reconstructive Surgery, \\ Pamukkale University Hospital, ${ }^{4}$ Department of Pathology, Selcuk University Hospital, ${ }^{5}$ Department of Orthopedics and \\ Traumatology, Mevlana (Rumi) University Hospital, Konya, Turkey
}

*For correspondence: Email: ssenturk@mevlana.edu.tr; Tel: 4444200-1115; Fax: 903323229419

Received: 15 May 2015

Revised accepted: 1 August 2015

\begin{abstract}
Purpose: To investigate the re-endothelialization potential of erythropoietin (EPO) following microvascular anastomosis in rat femoral artery.

Methods: Ninety-six male Sprague-Dawley rats weighing between $300 \mathrm{~g}$ and $320 \mathrm{~g}$ were allocated randomly into two groups (control and EPO, $n=48$ ). Left femoral artery microvascular anastomosis was performed in the rats. The control group was given $0.5 \mathrm{~mL}$ of $0.09 \% \mathrm{NaCl}$ subcutaneously $48 \mathrm{~h}$ postoperatively while the EPO group was given $150 \mathrm{U} / \mathrm{kg}$ recombinant human erythropoietin subcutaneously $48 \mathrm{~h}$ post-operatively. Tissue was harvested from each group after 1, 3, 5, and 7 days. All of the rats were sacrificed for morphometric analysis. Each arterial segment was analyzed morphometrically using Clemex Image Analysis software by a single examiner. The cross-sectional area of the media and neointima was measured and the intima/media ratio was calculated. Hematocrit measurement was carried out for all the rats.

Results: The I/M ratio differed significantly $(p<0.05)$ between the control and erythropoietin groups, at all time-points. The hematocrit was significantly $(p<0.05)$ lower in the control group than in the erythropoietin groups on day 7 , but not on the other days.

Conclusion: This study demonstrates that erythropoietin markedly inhibits neointima formation with accelerated re-endothelialization in rat femoral arteries following microvascular anastomosis.
\end{abstract}

Keywords: Erythropoietin, Microvascular anastomosis, Re-endothelialization, Hematocrit, Neointima/media ratio

Tropical Journal of Pharmaceutical Research is indexed by Science Citation Index (SciSearch), Scopus, International Pharmaceutical Abstract, Chemical Abstracts, Embase, Index Copernicus, EBSCO, African Index Medicus, JournalSeek, Journal Citation Reports/Science Edition, Directory of Open Access Journals (DOAJ), African Journal Online, Bioline International, Open-J-Gate and Pharmacy Abstracts

\section{INTRODUCTION}

Microsurgical procedures require much labor, time, and funding. Problems that arise with anastomosis account for most of the complications that follow microsurgical procedures. Delayed re-endothelialization at the anastomosis line leads to thrombus formation and anastomotic blockage for various reasons. The main contributor to a successful microsurgical procedure is safe vessel anastomosis. The faster the healing of the anastomosis is, the fewer complications that result.

There are many growth factors and hormones that stimulate angiogenesis. Vascular endothelial growth factor (VEGF) is an important growth factor with strong mitogenic effects on endothelial cells [1-4]. Erythropoietin (EPO) is a 
critical regulator of the proliferation of erythroid and endothelial precursors, but its role as a potential re-endothelialization agent in microvascular anastomosis is unclear [5-8]. This study investigated the effect of erythropoietin on re-endothelialization histologically.

\section{EXPERIMENTAL}

The study was approved by the Ethics Committee of the Experimental Medical Research and Application Center of Selçuk University and the Principles of Laboratory Animal Care (NIH publication No. 85-23, revised 1985). We used 96 male Sprague-Dawley rats weighing $300-320 \mathrm{~g}$. The animals were kept in the same room at $22 \pm 1{ }^{\circ} \mathrm{C}$ under standard physical conditions and fed the same standard diet.

For the experiment, each animal was given intramuscular anesthesia with $35 \mathrm{mg} / \mathrm{kg}$ ketamine (Ketalar ${ }^{\circledR} 50 \mathrm{mg} / \mathrm{mL}$ vial, Pfizer) and 5 $\mathrm{mg} / \mathrm{kg}$ xylazine (Rompun® vial, Bayer). The animal was positioned on its back on the operating table. After shaving the left inguinal area, the skin was cleaned with antiseptic solution and a 2-cm incision was made on the left inguinal crease with a no. 15 blade. After careful dissection, the femoral neurovascular bundle was identified. The femoral artery was exposed using an $8 \times$ loupe and clamped with an Acland approximator (00409A; S\&T, Switzerland), then cut vertically and $0.1 \%$ bupivacaine (Marcaine, AstraZeneca $\AA$ ) was applied locally to reduce vessel spasm.

After cleaning the adventitia, two tension sutures were inserted at $120^{\circ}$ angle with 10/0-75 $\mu \mathrm{m}$, round polyamide needles (Ethicon EthilonW2850-J\&J). These sutures were hung around the Acland approximator. After repairing the anterior wall, the approximator was rotated 180 degrees. Then, the posterior wall was repaired. After fixing the approximator, the microclamp was removed. An average of six sutures was inserted for each anastomosis. Then, hemostasis was performed and the skin was closed with 4/0 silk sutures. The mean anastomosis time was 30 min, while the total operating time was 40 min for a rat. The animals were divided into control $(n=$ $48)$ and EPO $(n=48)$ groups. The control group was given $0.5 \mathrm{~mL}$ of $0.09 \% \mathrm{NaCl}$ subcutaneously $48 \mathrm{~h}$ post-operatively. The EPO group was given $150 \mathrm{U} / \mathrm{kg}$ recombinant human erythropoietin (Eprex 2000 IU rHuEPO vial) subcutaneously $48 \mathrm{~h}$ post-operatively.

Tissue was harvested from each group after 1, 3 , 5 , and 7 days. For this, each animal was again anesthetized with intramuscular ketamine and xylazine, as described above, and placed in the supine position on the operating table. After removing the sutures from the wound, the anastomosis area was dissected with the aid of an $8 \times 190-\mathrm{mm}$ loupe (Prismen Lupe KS, Carl Zeiss, Germany). A 1-mm length was taken from the femoral artery including the anastomosis.

\section{Hematological analysis}

Blood samples collected from carotid arteries. The Blood samples were taken from all animals and the hematocrit was determined using Roche Diagnostic Sysmex KX 21-N (Japan 2005).

\section{Histological analysis}

The tissue samples were fixed in $10 \%$ formaldehyde, followed by Autotechnicon (Shandon Citadel 2000). After $24 \mathrm{~h}$ they were embedded in paraffin blocks vertically and $5-\mu \mathrm{m}$ cross-sections were prepared from these paraffin blocks using a microtome. The cross-sections were stained with Verhoeff-Van Gieson stain and examined using a Nikon Eclipse E400 microscope.

They were photographed with a Nikon Coolpix 5000 digital camera. The photographs were analyzed using Clemex Image Analysis and the areas of the tunica intima and media were calculated (Figure 3).

\section{Statistical analysis}

The data were analyzed using Statistical Package for the Social Sciences (SPSS), version 16.0, for Windows. One-sample KolmogorovSmirnov test was used to analyze the distribution of continuous variables. Continuous variables with normal distributions were compared between the two groups using Students t-test. All significance levels were two-tailed and set at $p<$ 0.05 .

\section{RESULTS}

The results (Figs $1-3$ ) of our investigation can be summarized as follows. First, in the early stage ( 1 - 3 days), EPO reduced intimal hyperplasia by increasing endothelialization at the microvascular anastomosis line. Second, at 5 -7 days, intimal hyperplasia is insignificant due to the completion of endothelialization. Third, the hematocrit did not increase significantly following the use of EPO in the early stage ( $1-3$ days), but increased significantly at $5-7$ days. 


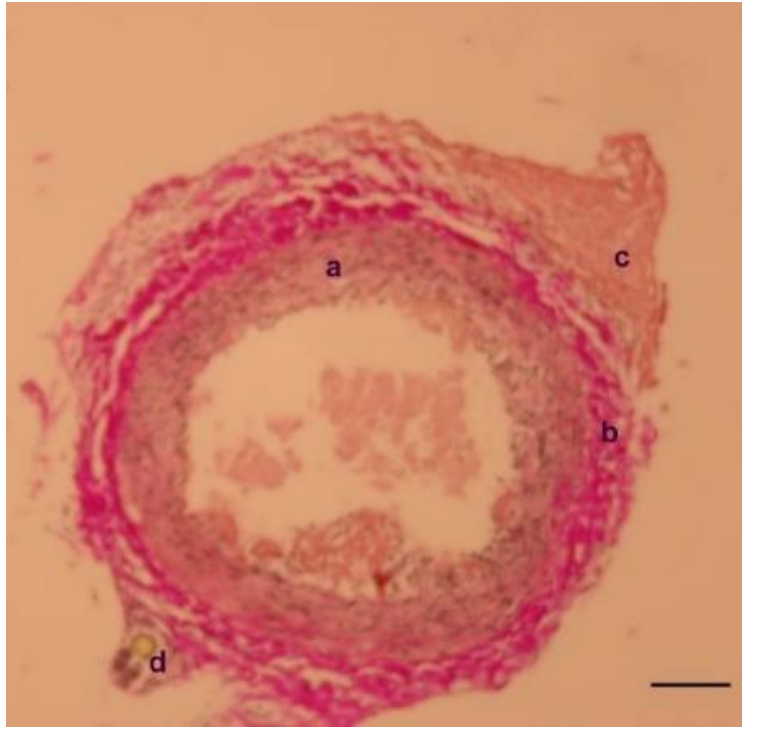

Figure 1: Appearance of control group on day 7 after Verhoeff-Van Gieson staining: tunica intima. I/M (a/b) $=0.78$

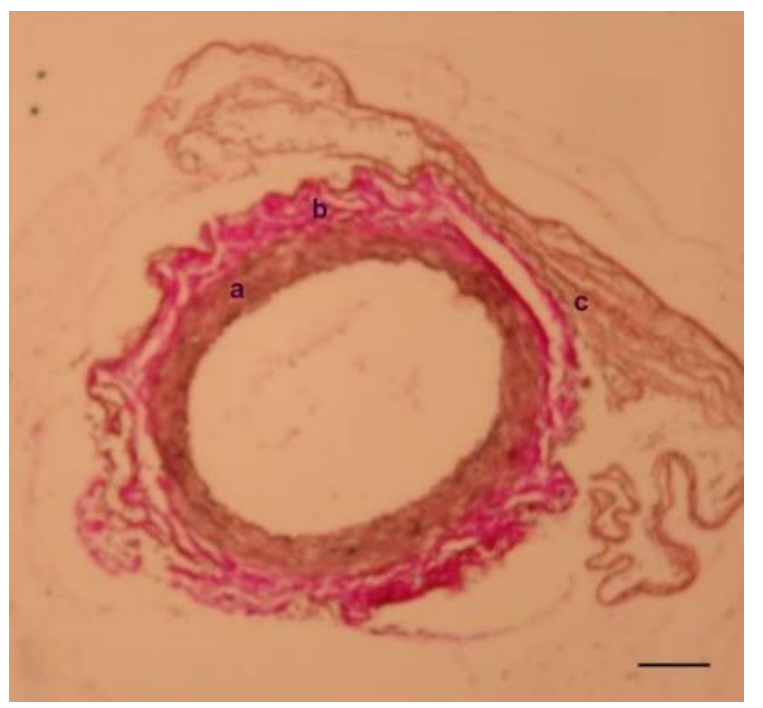

Figure 2: Appearance of the erythropoietin group on day 7 after Verhoeff-Van Gieson staining. $\mathrm{I} / \mathrm{M}(\mathrm{a} / \mathrm{b})=$ 0.69

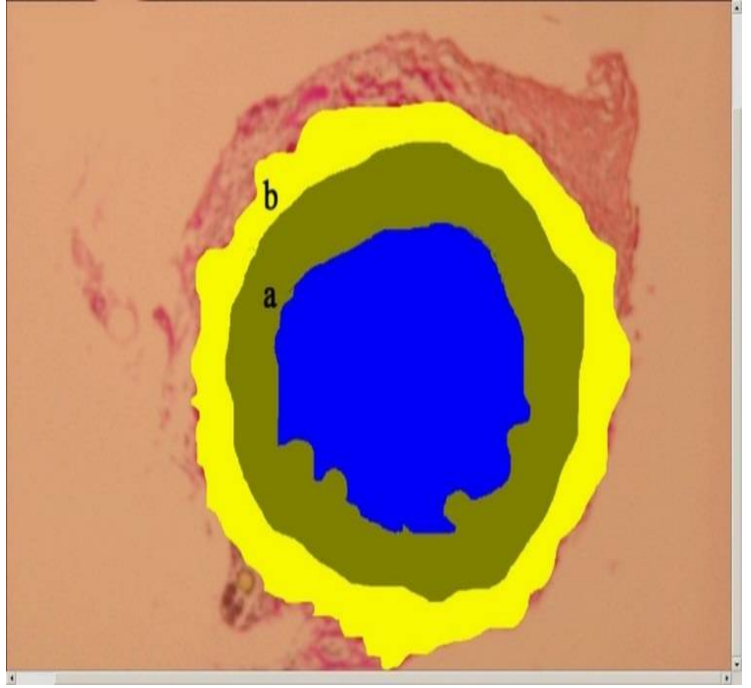

Figure 3: Tunica intima and tunica media areas. I/M $(a / b)=0.78$

The mean intima/media $(\mathrm{l} / \mathrm{M})$ ratio, hematocrit and $\mathrm{p}$-values of all groups are shown in Table 1. $\mathrm{I} / \mathrm{M}$ ratio differed significantly $(p<0.05)$ between control and erythropoietin groups, at all-time points. Hematocrit was significantly $(p<0.05)$ lower in the control group than in the erythropoietin groups on day 7, but not on the other days.

\section{DISCUSSION}

The role of microvascular surgery in plastic surgery has been increasing gradually. The main condition for a successful microsurgical procedure is a safe vessel anastomosis. The faster the healing of the anastomosis is, the fewer complications there will be. The results of our investigation can be summarized as follows: This study supports other recent studies of angiogenic factors and underlines the importance of EPO in microvascular surgery. Based on these positive effects, we believe that EPO will reduce complications and increase the success rate of microsurgery.

Table 1: Group statistics for I/M and hematocrit

\begin{tabular}{lcccc}
\hline Parameter & Day & $\begin{array}{c}\text { Erythropoietin } \\
\text { (mean } \pm \text { SD) }\end{array}$ & $\begin{array}{c}\text { Control } \\
\text { (mean } \pm \text { SD) }\end{array}$ & $\boldsymbol{P}^{\text {-value }}{ }^{\text {a }^{2}}$ \\
\hline Intima/media ratio & 1 & $0.97 \pm 0.02$ & $1.04 \pm 0.05$ & $\mathbf{0 . 0 0 1}$ \\
& 3 & $0.86 \pm 0.009$ & $1.01 \pm 0.04$ & $\mathbf{0 . 0 0 0}$ \\
& 5 & $0.69 \pm 0.01$ & $0.80 \pm 0.02$ & $\mathbf{0 . 0 0 0}$ \\
\hline Hematocrit & 7 & $0.69 \pm 0.47$ & $0.76 \pm 0.2$ & $\mathbf{0 . 0 0 0}$ \\
& 1 & $40.83 \pm 3.27$ & $40.41 \pm 2.71$ & 0.737 \\
& 3 & $41.58 \pm 2.93$ & $41 \pm 2.82$ & 0.625 \\
& 5 & $43.83 \pm 3.24$ & $41.25 \pm 3.19$ & 0.183 \\
& 7 & $45.33 \pm 1.37$ & $43.16 \pm 2.16$ & $\mathbf{0 . 0 0 8}$ \\
\hline
\end{tabular}

\footnotetext{
${ }^{\text {a }}$ Student's $t$-test
} 
Many growth factors and hormones stimulate angiogenesis [1-3]. VEGF is an important growth factor that has a strong mitogenic effect on endothelial cells [4]. There are many other angiogenic growth factors and hormones, but only a limited number of studies have examined them. EPO is one of these factors. Cytokines and especially EPO-related hematopoiesis are thought to play a role in angiogenesis as hematopoietic and endothelial cell lines are derived from the same common ancestor [5-8].

Ribatti et al showed that cytokines previously thought to be specific for the hematopoietic system affect endothelial cell functions, including angiogenesis [9]. However, there are few studies of the angiogenic effects of EPO compared to other angiogenic factors (VEGF and fibroblast growth factor (FGF)). VEGF is the most important angiogenic factor [10].

In a study of myocardial tissue cultures from 111 patients, Jaquet et al showed that the capillary growth rate was $220 \%$ with VEGF versus $230 \%$ with EPO [11]. This study showed that EPO was as effective as VEGF and supports our results. However, Nitta et al stated that EPO increased DNA synthesis in cattle glomerular endothelial cell cultures and this stimulated VEGF synthesis [12]. EPO increases the synthesis of endothelin 1 , via thrombin and angiotensin, two potential stimulators of ET-1 $[5,6]$. Salani et al studied the role of ET-1 in angiogenesis in human umbilical vein endothelial cell (HUVEC) cultures in comparison to VEGF, and found that ET-1 increases the angiogenesis induced by VEGF [14].

The potential interaction between VEGF and ET1 was also investigated by Matsuura et al, who proved that VEGF increases the ET-1 secretion in endothelial cells [13]. All of these studies show that many factors interact in angiogenesis. In addition to the direct angiogenic effect of EPO, it also has indirect angiogenic effects by increasing the production of other factors.

Vascular injuries cause an increase in extracellular matrix, the proliferation of smooth muscle cells, and formation of neointima via cell proliferation and migration [15,16]. Endothelial cells inhibit intimal hyperplasia by regulating the growth of smooth muscle cells $[15,17]$. However, rapid re-endothelialization inhibits intimal hyperplasia via thrombus formation [18-23]. These data suggest that there is a reverse relationship between intimal hyperplasia and reendothelialization.
Based on this information, many studies evaluating re-endothelialization have measured the neointima and media, and their ratio has been accepted as an indicator of reendothelialization [20-24]. These values are calculated from a histomorphometric analysis and the resulting numerical data indicate that it is a sensitive and an effective method. We used Clemex Image Analysis for the morphometric analysis. Other techniques used to evaluate reendothelialization are macroscopic photomicrography with Evans blue staining and fluorescence microscopy [21,23]. These techniques are more subjective than morphometric analysis. Morphometric field analysis is useful in the rat femoral artery reanastomosis model because the injury site in the endothelium is so small that it cannot be quantified sensitively using photomicrographic techniques.

Comparing the $\mathrm{I} / \mathrm{M}$ ratios calculated in the morphometric analysis, it was found that the intima and media areas were lower than in the other groups, but their ratio $(\mathrm{I} / \mathrm{M})$ was higher. This shows that the tunica intima responds more rapidly and intensely to the injury at the anastomosis line than the tunica media.

In a histological study, Weinstein et al showed that elastic and muscular elements do not regenerate like the endothelium, and the response of the media layer to healing is slower than the intima [25]. Since the intimal hyperplasia in the control group was lower than in the erythropoietin group on day 1 , it is thought that even a single dose of EPO has powerful positive effects on the endothelium. In both groups, the intima and media areas increased on the third day, while their ratio decreased. This showed that the intimal hyperplasia decreased in both the control and erythropoietin groups.

On the third day, the intima was thinner than on the first day; therefore, the re-endothelialization activity was rapid on the third day $[25,26]$. Less intimal hyperplasia was seen with the EPO activity in this group. On days 5 and 7 , there was no substantial increase in the intima and the $\mathrm{I} / \mathrm{M}$ ratio was low because re-endothelialization was complete [26-28]. The $\mathrm{I} / \mathrm{M}$ values were significant in all groups $(p<0.05)$. This showed that erythropoietin decreased intimal hyperplasia by increasing re-endothelialization.

In this study, EPO was administered to the experimental animals subcutaneously at 48 -hour intervals. Macdougall et al reported that the subcutaneous administration of EPO was the best treatment [29]. Following subcutaneous 
injection, to maintain a high EPO concentration in blood, the injection must be repeated every $48 \mathrm{~h}$. The hemoglobin increases markedly when EPO is used in chronic renal failure for long periods [30]. The main side effect is hypertension in patients treated with EPO [31]. However, lowerdose EPO treatment and careful selection of the hemoglobin target decreases the incidence of hypertension [31]. In a study of healthy individuals, McMahon et al did not observe hypertension in any of the subjects [32]. Saray et al reported that there was no significant difference in arterial blood pressure and hematocrit with short-term EPO use, but there was a significant difference with long-term use [33]. Therefore, we used low-dose EPO. In our study, the hematocrit was minimally higher in experimental groups 1 to 3 than in the controls, but the difference was not significant, while the difference was significant in group 4 . These values might have resulted from the low-dose, short-term EPO use.

\section{CONCLUSION}

The findings of this study support other recent reports of angiogenic factors and underline the importance of EPO in microvascular surgery. It appears that EPO has two positive effects on microsurgery. First, it increases endothelialization on the anastomosis line and, secondly, it enhances flap vascularity. Based on these positive effects, it seems likely that EPO will reduce complications and increase the success rate of microsurgery. In this way, patients will not lose the opportunity for treatment, while physicians will be able to increase their success rates.

\section{REFERENCES}

1. Risau W. Mechanisms of angiogenesis. Nature 1997; 386: 671-674.

2. Scholz D, Cai WJ, Schaper W. Arteriogenesis, a new concept of vascular adaptation in occlusive disease. Angiogenesis 2001; 4: 247-257.

3. Ferrara N. Davis-Smyth, T. The biology of vascular endothelial growth factor. Endocr Rev 1997; 18: 423.

4. Schweiki D, Itin A, Soffer D, Keshet E. Vascular endothelial growth factor induced by hypoxia may mediate hypoxia-initiated angiogenesis. Nature 1992; 359: 843-845.

5. Anagnostou A, Lee ES, Kessimian N Levinson R, Steiner $M$. Erythropoietin has a mitogenic and positive chemotactic effect on endothelial cells. Proc Natl Acad Sci USA 1990; 87: 5978-5982.
6. Liefelt L, Schmidt-Ott KM, Orzechowski HD, Distler A, Paul M. Transcriptional regulation of endothelin-1 by erythropoietin in endothelial cells. J Cardiovasc Pharmacol 1998; 31: 464-466.

7. Carlini RG, Dusso AS, Obialo CIAlvarez UM, Rothstein M. Recombinant human erythropoietin (rHuEPO) increases endothelin-1 release by endothelial cells. Kidney Int 1993; 43: 1010-1014.

8. Carlini RG, Reyes AA, Rothstein M. Recombinant human erythropoietin stimulates angiogenesis in vitro. Kidney Int 1995; 47: 740-745.

9. Ribatti D, Presta M, Vacca A, Ria R, Giuliani R, Dell'Era $P$, Nico B, Roncali L, Dammacco F. Human erythropoietin induces a pro-angiogenic phenotype in cultured endothelial cells and stimulates neovascularization in vivo. Blood 1999; 93: 26272636.

10. Folkman J, Klagsbrun M. Angiogenic factors. Sci 1987; 235: 442-447.

11. Jaquet K, Krause K, Tawakol-Khodai M, Geidel S, Kuck $K H$. Erythropoietin and VEGF exhibit equal angiogenic potential. Microvascular Res 2002; 64: 326-333.

12. Nitta K, Uchida K, Kimata N, Honda K, Kobayashi $H$, Kawashima A, Yumura $W$, Nihei $H$. Recombinant human erythropoietin stimulates vascular endothelial growth factor release by glomerular endothelial cells. Eur J Pharmacol1999; 373: 121-124.

13. Matsuura A, Yamochi W, Hirata K, Kawashima S, Yokoama M. Stimulatory interaction between vascular endothelial growth factor and endothelin-1 on each gene expression. Hypertension 1998; 32: 89-95.

14. Salani D, Taraboletti G, Rosanò L, Di Castro V, Borsotti $P$, Giavazzi R, Bagnato A.Endothelin-1 induces an angiogenic Phenotype in cultured endothelial cells and stimulates neovascularization in vivo. Am J Path 2000; 157: 1703-1711.

15. Clowes AW, Reidy MA, Clowes MM. Kinetics of cellular proliferation after arterial injury, smooth muscle growth in the absence of endothelium. Lab Invest 1983; 49: 327-333.

16. Haudenschild CC, Schwartz SM. Endothelial regeneration, II; restitution of endothelial continuity. Lab Invest 1979; 41: 407-418.

17. Meurice T, Bauters C, Auffray JL, Vallet B, Hamon M, Valero F, Van Belle E, Lablanche JM, Bertrand ME. Basic fibroblast growth factor restores endotheliumdependent responses after balloon injury of rabbit arteries. Circulation 1996; 93: 18-22.

18. Gerber HP, McMurtrey A, Kowalski J, Yan M, Keyt BA, Dixit $V$, Ferrara N. Vascular endothelial growth factor regulates endothelial cell survival through the phosphatidylinositol 3'-kinase/Akt signal transduction pathway: requirement for Flk-1/KDR activation. J Biol Chem. 1998; 273: 30336-30343.

19. Morales-Ruiz M, Fulton D, Sowa G, Languino LR, Fujio $Y$, Walsh K, Sessa WC. Vascular endothelial growth

Trop J Pharm Res, September 2015; 14(9): 1633 
factor-stimulated actin reorganization and migration of endothelial cells is regulated via the serine/threonine kinase. Act Circ Res 2000; 86: 892896.

20. Numaguchi $Y$, Naruse $K$, Harada $M$, Osanai $H$, Mokuno $S$, Murase $K$, Matsui $H$, Toki $Y$, Ito $T$, Okumura $K$, et al. Prostacyclin synthase gene transfer accelerates reendothelialization and inhibits neointimal formation in rat carotid arteries after balloon injury. Arterioscler Thromb Vasc Biol 1999; 19: 727-733.

21. Walter DH, Rittig K, Bahlmann FH, Kirchmair R, Silver M. Statin therapy accelerates reendothelialization a novel effect involving mobilization and incorporation of bone marrow-derived endothelial progenitor cells. Circulation 2002; 105: 3017-3024.

22. Six I, Van Bell E, Bordet R, Corseaux D, Callebert J, Dupuis B, Bauters C, Bertrand ME. L-Arginine and $L$ NAME have no effects on the reendothelialization process after arterial balloon injury. Cardiovasc Res 1999; 43: 731-738.

23. Lee CW, Park SJ, Park SW, Kim JJ, Hong MK, Song JK. All-trans-retinoic acid attenuates neointima formation with acceleration of reendothelialization in ballooninjured rat aorta. J Korean Med Sci 2000; 15: 31-36.

24. Hasenstab D, Lea $H$, Clowes AW. Local plasminogen activator inhibitor type 1 overexpression in rat carotid artery enhances thrombosis and endothelial regeneration while inhibiting intimal thickening. Arterioscler Thromb Vasc Biol 2000; 20: 853-859.

25. Weinstein PR, Mehdorn HM, Szabo Z. Microsurgical anastomoses: vessel injury, regeneration, and repair. In Microsurgical composite tissue transplantation. St. Louis, CV Mosby, 1979; pp 111-144.
26. Ketchum LD, Wennen WW, Masters FW, Robinson DW. Experimental use of Pluronic F68 in microvascular surgery. Plast Reconst Surg 1974; 53: 288-295.

27. Hayhurst JW, O Brien BM. Experimental study of microvascular technique, patency rates, and related factors. Br J Plast Surg 1975; 28: 128-138.

28. Ts'ao C. Myointimal cells as a possible source of replacement for endothelial cells in the rabbit. Circ Res 1968; 23: 671-687.

29. Macdougall IC, Cavill I, Davies ME, Hutton RD, Coles GA, Williams JD. Subcutaneous recombinant erythropoietin in the treatment of renal anaemia in CAPD patients. Contrib Nephrol1989; 76: 219-226.

30. Grutzmacher $P$, Bergmann M, Weinreich T, Natterman $U$, Reimers E, Pollock M. Beneficial and adverse effects of correction of anaemia by recombinant human erythropoietin in patients on maintenance haemodialysis. Contrib Nephrol1988; 66: 104-113.

31. Brown AL, Tucker B, Baker LI, Raine AG. Seizures related to blood transfusion and erythropoietin treatment in patients undergoing dialysis. BMJ 1989; 299: 1258-1259.

32. McMahon $F$ G, Vargas $R$, Ryan M, Jain AK, Abels RI, Perry B, Smith IL.. Pharmacokinetics and effects of recombinant human erythropoietin after intravenous and subcutaneous injections in healthy volunteers. Blood 1990; 76: 1718-1722.

33. Saray A, Özakpınar R, Koç C, Serel S, Şen Z, Can Z. Effect of chronic and short-term erythropoietin treatment on random flap survival in rats: an experimental study. Laryngoscope 2003; 113: 85-89. 